\title{
Kemiripan dan Potensi Produksi Aksesi Pohpohan (Pilea trinervia Wight.) dari Beberapa Daerah di Jawa Barat
}

\author{
Similarity and Production Potential of Pohpohan \\ (Pilea trinervia Wight.) Landraces from Several Areas in West Java
}

\author{
Sopiana $^{1}$, Anas Dinurrohman Susila ${ }^{2 *}$, Muhamad Syukur ${ }^{2}$ \\ ${ }^{1}$ Program Studi Agronomi dan Hortikultura, Sekolah Pascasarjana, Institut Pertanian Bogor \\ ${ }^{2}$ Departemen Agronomi dan Hortikultura, Fakultas Pertanian, Institut Pertanian Bogor \\ (Bogor Agricultural University), Jl. Meranti, Kampus IPB Darmaga, Bogor 16680, Indonesia
}

Diterima 26 Juli 2017/Disetujui 6 Maret 2018

\begin{abstract}
Pohpohan (Pilea trinervia Wight.) is potential indigenous vegetable to be developed as a commercial vegetables. The objectives of this research were to observe similarity and production potential of pohpohan landraces from several areas in West Java. Result based on cluster analysis at nine similarity scale, thirteen exploration pohpohan landraces were grouped into three clusters. Clusters I consisted of Warung Loa, Tugu Selatan, Palasari, Langensari, Kayu Ambon, Lebak Muncang, Situsari, Sukalilah and Lebaksiuh. Clusters II consisted of Curug Rendeng, Argalingga and Linggarjati and clusters III was Bobojong. Result from further test using Duncan Multiple Range Test (DMRT), Warung Loa is a leading landrace because showed the best result on plant height, primary branches number, leaf width, yield per plot and plant productivity.
\end{abstract}

Keywords: Cluster analysis, exploration, indigenous vegetable

\section{ABSTRAK}

Pohpohan (Pilea trinervia Wight.) merupakan sayuran indigenous yang potensial dikembangkan sebagai sayuran komersil. Tujuan penelitian ini adalah untuk mengetahui kemiripan dan potensi produksi aksesi pohpohan dari beberapa daerah di Jawa Barat. Berdasarkan hasil analisis gerombol pada skala kemiripan sembilan, tiga belas aksesi pohpohan hasil eksplorasi dikelompokkan menjadi tiga gerombol. Gerombol I terdiri atas Warung Loa, Tugu Selatan, Palasari, Langensari, Kayu Ambon, Lebak Muncang, Situsari, Sukalilah dan Lebaksiuh. Gerombol II terdiri atas Curug Rendeng, Argalingga dan Linggarjati. Gerombol III adalah Bobojong. Berdasarkan uji lanjut Duncan Multiple Range Test (DMRT), aksesi Warung Loa merupakan aksesi yang paling unggul karena menunjukkan hasil yang terbaik pada tinggi tanaman, jumlah cabang primer, lebar daun, hasil panen per petak, dan produktivitas tanaman.

Kata kunci: Analisis gerombol, eksplorasi, sayuran indigenous

\section{PENDAHULUAN}

Pohpohan (Pilea trinervia Wight.) merupakan sayuran indigenous yang potensial dikembangkan sebagai tanaman komersil (Santosa et al., 2015). Bagian tanaman pohpohan yang dikonsumsi yaitu daun mudanya. Beberapa hasil penelitian menunjukkan bahwa daun pohpohan memiliki aktivitas antioksidan (Andarwulan et al., 2010; Endrini, 2011). Pohpohan termasuk famili Urticaceae, memiliki 600-715 spesies dan merupakan genus terbesar Urticaceae (Monro, 2004). Pohpohan ditemukan di daerah tropis dan subtropis di seluruh dunia, kecuali di Australia, Selandia Baru, dan Eropa (Monro et al., 2012).

\footnotetext{
* Penulis untuk korespondensi. e-mail: anasdsusila@gmail.com
}

Menurut Opabode dan Adebooye (2005) masalah utama pengembangan sayuran indigenous yaitu plasma nutfah yang tidak terkarakterisasi dan terkoleksi dengan baik. Sampai saat ini karakterisasi aksesi pohpohan masih sedikit dilakukan di Indonesia. Penelitian Putrasamedja (2005) di Kabupaten Subang, Karawang, dan Purwakarta hanya mengkarakterisasi satu aksesi pohpohan. Selain itu, bahan tanam sebagai sumber pengembangan tanaman pohpohan belum jelas identitasnya dan produktivitasnya juga masih rendah. Hasil penelitian Ekawati et al. (2010) menunjukkan produktivitas tanaman pohpohan mencapai $360.50 \mathrm{~kg} \mathrm{ha}^{-1}$. Hal ini dapat ditingkatkan dengan cara pemilihan bahan tanam yang tepat atau aksesi yang unggul.

Penelitian ini merupakan langkah awal untuk pengembangan sayuran indigenous khususnya pohpohan sehingga bermanfaat dimasa yang akan datang. Tujuan 
penelitian adalah untuk mengetahui kemiripan dan potensi produksi aksesi pohpohan (Pilea trinervia Wight.) dari beberapa daerah di Jawa Barat.

\section{BAHAN DAN METODE}

\section{Eksplorasi pohpohan}

Eksplorasi dilaksanakan mulai bulan Desember 2013 sampai dengan Februari 2014 di beberapa daerah di Jawa Barat yaitu di Kabupaten Bogor, Bandung Barat, Subang, Majalengka, Kuningan, Garut, Sukabumi, dan Bandung. Total aksesi hasil eksplorasi yang dikoleksi yaitu 13 aksesi antara lain Warung Loa (PA1), Bobojong (PA2), Tugu Selatan (PA3), Palasari (PA4), Curug Rendeng (PA5), Langensari (PA6), Kayu Ambon (PA7), Lebak Muncang (PA8), Argalingga (PA9), Linggarjati (PA10), Situsari (PA11), Sukalilah (PA12) dan Lebaksiuh (PA13).

Karakterisasi sifat morfologi aksesi pohpohan hasil eksplorasi

Percobaan 1 dilaksanakan pada bulan Februari sampai dengan April 2014 di Kebun Percobaan IPB Tajur. Bahan tanaman yang digunakan yaitu 13 aksesi hasil eksplorasi. Masing-masing aksesi terdiri dari 10 tanaman dan kemudian dilakukan karakterisasi secara morfologi. Kemiripan karakteristik antar aksesi pohpohan dilakukan berdasarkan analisis gerombol, menggunakan software IBM SPSS Statistic 20. Analisis gerombol dilakukan berdasarkan karakter morfologi tumbuhan (Tjitrosoepomo, 1987). Kesamaan karakteristik diukur menggunakan ukuran kedekatan antar objek berupa ukuran kemiripan atau ketakmiripannya (Ariawan et al., 2013). Mengukur kemiripan antar objek umumnya menggunakan jarak euclidean (akar ciri). Menurut Yunianti et al. (2007) semakin kecil jarak euclidean antar dua genotipe maka semakin mirip genotipe tersebut. Pengelompokan kemiripan karakter antar aksesi dapat dilihat berdasarkan analisis gerombol.

Pelaksanaan percobaan 1 dimulai dengan pembibitan stek pohpohan, yang berupa stek batang dengan panjang 10 $\mathrm{cm}$. Stek ditanam dalam polybag ukuran $10 \mathrm{~cm}$ x $10 \mathrm{~cm}$ dengan media tanam arang sekam dan pupuk kandang sapi dengan perbandingan 1:1. Penyiraman dilakukan setiap hari. Pemupukan bibit menggunakan larutan pupuk daun yaitu $\mathrm{N}, \mathrm{P}_{2} \mathrm{O}_{5}, \mathrm{~K}_{2} \mathrm{O}, \mathrm{Mg}(20-15-15-1) 2 \mathrm{~g} \mathrm{~L}^{-1}$ air dengan dosis 25 $\mathrm{mL}$ per tanaman dan disiram 4 hari sekali. Bibit dipindah ke bedengan pada umur 6 minggu setelah tanam (MST). Ukuran bedengan $5 \mathrm{~m}$ x $1 \mathrm{~m}$ dengan tinggi bedengan $20 \mathrm{~cm}$. Jarak antar bedengan $60 \mathrm{~cm}$ dan jarak tanam double row 50 $\mathrm{cm}$ x $50 \mathrm{~cm}$. Penyiraman dilakukan setiap hari. Naungan yang digunakan yaitu paranet $75 \%$ dengan intensitas cahaya $220 \mu \mathrm{mol} \mathrm{m} \mathrm{m}^{-2}$ (PPF = photosynthesis photon flux $)$. Pemupukan tanaman pohpohan menggunakan larutan NPK (15-15-15) $90 \mathrm{~g} \mathrm{~L}^{-10}$ air dengan dosis $250 \mathrm{~mL}$ per tanaman dan diberikan pada umur 4 MST. Larutan pupuk daun yang digunakan yaitu $\mathrm{N}, \mathrm{P}_{2} \mathrm{O}_{5}, \mathrm{~K}_{2} \mathrm{O}, \mathrm{Mg}$ (20-15-15-1) $1 \mathrm{~g} \mathrm{~L}^{-1}$ air dengan dosis $25 \mathrm{~mL}$ per tanaman dan diberikan seminggu sekali.
Pengamatan karakter morfologi pohpohan merujuk pada buku morfologi tumbuhan (Tjitrosoepomo, 1987). Karakter yang diamati yaitu tipe tanaman, total tinggi tanaman, kerapatan tanaman, pewarnaan antosianin batang, intensitas pewarnaan antosianin ujung batang, daun berbulu, bentuk helai daun, panjang helai daun, lebar helai daun, panjang daun terminal, lebar daun terminal, bentuk tulang daun, kecerahan helai daun, profil di penampang helai daun, gelombang daun, tepi bergelombang helai daun, tepi bergerigi helai daun, kedalaman gerigi tepi helai daun, ujung daun, pangkal daun, panjang tangkai daun, panjang ruas rata-rata pada batang berbunga (akhir pembungaan), bentuk bunga, warna daun mahkota bunga, dan waktu berbunga.

\section{Evaluasi potensi produksi}

Percobaan 2 dilaksanakan bulan Mei sampai dengan Agustus 2014 di Kebun Percobaan IPB Tajur, menggunakan rancangan kelompok lengkap teracak (RKLT) faktor tunggal, yaitu 3 aksesi sebagai perlakuan dengan 4 ulangan sebagai kelompok, sehingga diperoleh 12 satuan percobaan. Masing-masing satuan percobaan terdiri dari 20 tanaman.

Pelaksanaan percobaan 2 dilakukan sama seperti percobaan 1. Bahan tanam yang digunakan adalah stek pohpohan dari 3 aksesi hasil seleksi percobaan 2 berdasarkan hasil analisis gerombol. Aksesi tersebut antara lain Warung Loa, Linggarjati, dan Bobojong. Pemanenan pohpohan dilakukan saat tanaman berumur 6, 8, dan 10 MST. Panen dilakukan dengan pemotongan tunas muda sekitar $15 \mathrm{~cm}$.

Peubah yang diamati adalah tinggi tanaman $(\mathrm{cm})$, diameter batang $(\mathrm{cm})$, jumlah cabang primer, panjang daun $(\mathrm{cm})$, lebar daun $(\mathrm{cm})$, umur mulai berbunga (HST), hasil panen per petak $(\mathrm{g})$, dan produktivitas tanaman $\left(\mathrm{kg} \mathrm{ha}^{-1}\right)$. Data diolah dengan analisis ragam pada taraf 5\% jika terdapat perbedaan yang nyata maka dilakukan uji lanjut Duncan Multiple Range Test (DMRT).

\section{HASIL DAN PEMBAHASAN}

\section{Eksplorasi Pohpohan}

Eksplorasi di beberapa daerah di Jawa Barat berhasil mengoleksi 13 aksesi pohpohan (Tabel 1). Aksesi pohpohan hasil eksplorasi ditemukan pada ketinggian 631-1288 m dpl.

Karakterisasi sifat morfologi aksesi pohpohan hasil eksplorasi

Karakterisasi 13 aksesi pohpohan dilakukan berdasarkan morfologi tumbuhan (Tjitrosoepomo, 1987). Menurut Ram et al. (2008) karakterisasi dapat membantu dalam mengidentifikasi keunikan suatu genotipe untuk perbaikan tanaman.

Aksesi-aksesi yang ditanam pada percobaan 1 merupakan spesies yang sama yang berasal dari satu wilayah dengan perbanyakan yang sama yaitu secara vegetatif (stek). Berdasarkan hasil karakterisasi, 13 aksesi pohpohan memiliki kemiripan beberapa karakter yaitu tipe 
Tabel 1. Hasil eksplorasi aksesi pohpohan dari beberapa daerah di Jawa Barat

\begin{tabular}{lllclc}
\hline Aksesi & Kode & Kabupaten & Elevasi (m dpl) & \multicolumn{2}{c}{ Posisi geografis } \\
\hline Warung Loa & PA1 & Bogor & 712 & $\mathrm{~S}: 06^{\circ} 32^{\prime} 54^{\prime \prime}$ & $\mathrm{T}: 106^{\circ} 38^{\prime} 30^{\prime \prime}$ \\
Bobojong & PA2 & Bogor & 707 & $\mathrm{~S}: 06^{\circ} 39^{\prime} 51^{\prime \prime}$ & $\mathrm{T}: 106^{\circ} 44^{\prime} 46^{\prime \prime}$ \\
Tugu Selatan & PA3 & Bogor & 963 & $\mathrm{~S}: 06^{\circ} 41^{\prime} 17^{\prime \prime}$ & $\mathrm{T}: 106^{\circ} 57^{\prime} 00^{\prime \prime}$ \\
Palasari & PA4 & Subang & 822 & $\mathrm{~S}: 06^{\circ} 43^{\prime} 50^{\prime \prime}$ & $\mathrm{T}: 107^{\circ} 40^{\prime} 20^{\prime \prime}$ \\
Curug Rendeng & PA5 & Subang & 631 & $\mathrm{~S}: 06^{\circ} 41^{\prime} 29^{\prime \prime}$ & $\mathrm{T}: 107^{\circ} 39^{\prime} 34^{\prime \prime}$ \\
Langensari & PA6 & Bandung Barat & 1,253 & $\mathrm{~S}: 06^{\circ} 49^{\prime} 36^{\prime \prime}$ & $\mathrm{T}: 107^{\circ} 38^{\prime} 14^{\prime \prime}$ \\
Kayu Ambon & PA7 & Bandung Barat & 1,247 & $\mathrm{~S}: 06^{\circ} 49^{\prime} 31^{\prime \prime}$ & $\mathrm{T}: 107^{\circ} 38^{\prime} 14^{\prime \prime}$ \\
Lebak Muncang & PA8 & Bandung & 703 & $\mathrm{~S}: 06^{\circ} 51^{\prime} 59^{\prime \prime}$ & $\mathrm{T}: 106^{\circ} 55^{\prime} 03^{\prime \prime}$ \\
Argalingga & PA9 & Majalengka & 1,288 & $\mathrm{~S}: 06^{\circ} 53^{\prime} 48^{\prime \prime}$ & $\mathrm{T}: 108^{\circ} 21^{\prime} 28^{\prime \prime}$ \\
Linggarjati & PA10 & Kuningan & 818 & $\mathrm{~S}: 06^{\circ} 53^{\prime} 05^{\prime \prime}$ & $\mathrm{T}: 108^{\circ} 28^{\prime} 04^{\prime \prime}$ \\
Situsari & PA11 & Garut & 687 & $\mathrm{~S}: 07^{\circ} 15^{\prime} 26^{\prime \prime}$ & $\mathrm{T}: 107^{\circ} 47^{\prime} 13^{\prime \prime}$ \\
Sukalilah & PA12 & Garut & 1,198 & $\mathrm{~S}: 07^{\circ} 15^{\prime} 04^{\prime \prime}$ & $\mathrm{T}: 107^{\circ} 47^{\prime} 04$ \\
Lebaksiuh & PA13 & Sukabumi & 703 & $\mathrm{~S}: 06^{\circ} 51^{\prime} 59^{\prime \prime}$ & $\mathrm{T}: 106^{\circ} 55^{\prime} 03^{\prime \prime}$ \\
\hline
\end{tabular}

tanaman, total tinggi tanaman, kerapatan tanaman, dan pewarnaan antosianin batang (Tabel 2), daun berbulu, profil di penampang helai daun, dan gelombang daun (Tabel 3), bentuk helai daun, bentuk tulang daun, tepi bergelombang helai daun, tepi bergerigi helai daun, kedalaman gerigi tepi helai daun, ujung daun, dan pangkal daun (Tabel 4), panjang tangkai daun (Tabel 5), panjang ruas rata-rata batang berbunga, bentuk bunga, warna daun mahkota bunga, dan waktu berbunga (Tabel 6).

Besarnya kemiripan disebabkan oleh aksesi yang berasal dari spesies dan negara yang sama dengan perbanyakan yang sama yaitu secara vegetatif. Indriani et al. (2008) mengatakan bahwa aksesi yang berasal dari satu negara atau letak georafis yang sama cenderung memiliki jarak genetik yang dekat. Basha dan Sujatha (2007), menyatakan bahwa tanaman yang diperbanyak secara vegetatif memiliki sifat yang sama dengan induknya. Menurut Susantidiana et al. (2009), kemiripan antar aksesi yang besar menunjukkan bahwa aksesi-aksesi tersebut mempunyai hubungan kekerabatan yang dekat.

Tiga belas aksesi pohpohan hasil eksplorasi dikelompokkan menjadi tiga gerombol pada skala

Tabel 2. Karakter batang atau habitus 13 aksesi pohpohan

\begin{tabular}{|c|c|c|c|c|c|}
\hline \multirow[b]{2}{*}{ Aksesi } & \multicolumn{5}{|c|}{ Karakter } \\
\hline & Tipe tanaman & $\begin{array}{c}\text { Total tinggi } \\
\text { tanaman }^{\mathrm{a}}\end{array}$ & $\begin{array}{l}\text { Kerapatan } \\
\text { tanaman }^{\mathrm{b}}\end{array}$ & $\begin{array}{l}\text { Pewarnaan } \\
\text { antosianin } \\
\text { batang }^{c}\end{array}$ & $\begin{array}{c}\text { Intensitas pewarnaaan } \\
\text { antosianin ujung } \\
\text { batang }\end{array}$ \\
\hline Warung Loa & Semi tegak & Sedang & Longgar & Ada & Sedang \\
\hline Bobojong & Semi tegak & Pendek & Longgar & Ada & Sedang \\
\hline Tugu Selatan & Semi tegak & Sedang & Longgar & Ada & Sedang \\
\hline Palasari & Semi tegak & Sedang & Longgar & Ada & Sedang \\
\hline Curug Rendeng & Semi tegak & Sedang & Longgar & Ada & Kuat \\
\hline Langensari & Semi tegak & Sedang & Longgar & Ada & Sedang \\
\hline Kayu Ambon & Semi tegak & Sedang & Longgar & Ada & Sedang \\
\hline Lebak Muncang & Semi tegak & Sedang & Longgar & Ada & Sedang \\
\hline Argalingga & Semi tegak & Sedang & Longgar & Ada & Kuat \\
\hline Linggarjati & Semi tegak & Sedang & Longgar & Ada & Kuat \\
\hline Situsari & Semi tegak & Sedang & Longgar & Ada & Sedang \\
\hline Sukalilah & Semi tegak & Sedang & Longgar & Ada & Sedang \\
\hline Lebaksiuh & Semi tegak & Sedang & Longgar & Ada & Sedang \\
\hline
\end{tabular}

Keterangan: ${ }^{a}$ Pendek : $<30 \mathrm{~cm}$, sedang : 30-60 cm, tinggi $>60 \mathrm{~cm},{ }^{\text {b }}$ Rapat : tajuk antar tanaman bertemu, longgar $=$ tajuk antar tanaman tidak bertemu, ${ }^{\mathrm{c}}$ Ada : terdapat warna ungu pada batang, tidak ada : tidak terdapat warna ungu pada batang 
Tabel 3. Karakter daun 13 aksesi pohpohan

\begin{tabular}{lcccc}
\hline \multirow{2}{*}{ Aksesi } & Kecerahan & Karakter & \\
\cline { 2 - 5 } & $\begin{array}{c}\text { Daun } \\
\text { berbulu }\end{array}$ & $\begin{array}{c}\text { Profil di penampang } \\
\text { helai daun }\end{array}$ & $\begin{array}{c}\text { Gelombang tengah } \\
\text { helai daun }\end{array}$ & Adai daun \\
\hline Warung Loa & Ada & Sedang & Bentuk V & Ada \\
Bobojong & Ada & Lemah & Bentuk V & Ada \\
Tugu Selatan & Ada & Sedang & Bentuk V & Ada \\
Palasari & Ada & Sedang & Bentuk V & Ada \\
Curug Rendeng & Ada & Kuat & Bentuk V & Ada \\
Langensari & Ada & Sedang & Bentuk V & Ada \\
Kayu Ambon & Ada & Sedang & Bentuk V & Ada \\
Lebak Muncang & Ada & Sedang & Bentuk V & Ada \\
Argalingga & Ada & Kuat & Bentuk V & Ada \\
Linggarjati & Ada & Kuat & Bentuk V & Ada \\
Situsari & Ada & Sedang & Bentuk V & Ada \\
Sukalilah & Ada & Sedang & Bentuk V & \\
Lebaksiuh & Ada & Sedang & & \\
\hline
\end{tabular}

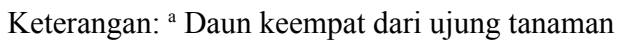

Tabel 4. Karakter bentuk daun 13 aksesi pohpohan

\begin{tabular}{lccccccc}
\hline & \multicolumn{5}{c}{ Karakter } & & \\
\cline { 2 - 4 } & Bentuk helai \\
daun & $\begin{array}{c}\text { Bentuk } \\
\text { tulang daun }\end{array}$ & $\begin{array}{c}\text { Tepi } \\
\text { Bergelombang } \\
\text { helai daun }\end{array}$ & $\begin{array}{c}\text { Tepi } \\
\text { bergerigi } \\
\text { helai } \\
\text { daun }\end{array}$ & $\begin{array}{c}\text { Kedalaman } \\
\text { gerigi tepi helai } \\
\text { daun }\end{array}$ & $\begin{array}{c}\text { Ujung daun } \\
\text { Pangkal } \\
\text { daun }\end{array}$ \\
\hline Warung Loa & Bulat telur & Melengkung & Sedang & Ada & Bergerigi sedang & Meruncing & Berlekuk \\
Bobojong & Bulat telur & Melengkung & Lemah & Ada & Bergerigi sedang & Meruncing & Berlekuk \\
Tugu Selatan & Bulat telur & Melengkung & Sedang & Ada & Bergerigi sedang & Meruncing & Berlekuk \\
Palasari & Bulat telur & Melengkung & Sedang & Ada & Bergerigi sedang & Meruncing & Berlekuk \\
Curug Rendeng & Bulat telur & Melengkung & Lemah & Ada & Bergerigi sedang & Meruncing & Berlekuk \\
Langensari & Bulat telur & Melengkung & Sedang & Ada & Bergerigi sedang & Meruncing & Berlekuk \\
Kayu Ambon & Bulat telur & Melengkung & Sedang & Ada & Bergerigi sedang & Meruncing & Berlekuk \\
Lebak Muncang & Bulat telur & Melengkung & Sedang & Ada & Bergerigi sedang & Meruncing & Berlekuk \\
Argalingga & Bulat telur & Melengkung & Lemah & Ada & Bergerigi sedang & Meruncing & Berlekuk \\
Linggarjati & Bulat telur & Melengkung & Lemah & Ada & Bergerigi sedang & Meruncing & Berlekuk \\
Situsari & Bulat telur & Melengkung & Sedang & Ada & Bergerigi sedang & Meruncing & Berlekuk \\
Sukalilah & Bulat telur & Melengkung & Sedang & Ada & Bergerigi sedang & Meruncing & Berlekuk \\
Lebaksiuh & Bulat telur & Melengkung & Sedang & Ada & Bergerigi sedang & Meruncing & Berlekuk \\
\hline
\end{tabular}

kemiripan 9 (Gambar 1). Gerombol I berjumlah 9 aksesi terdiri dari aksesi Warung Loa, Tugu Selatan, Palasari, Langensari, Kayu Ambon, Lebak Muncang, Situsari, Sukalilah dan Lebaksiuh; 9 aksesi ini memiliki kemiripan 100\%. Gerombol II berjumlah 3 aksesi terdiri dari aksesi Curug Rendeng, Argalingga dan Linggarjati; ketiga aksesi ini memiliki kemiripan 100\%. Pada gerombol III terdapat 1 aksesi yaitu Bobojong.
Karakter pembeda yang ditunjukkan masing-masing gerombol yaitu intensitas pewarnaan antosianin ujung batang, panjang helai daun, lebar helai daun, panjang daun terminal, lebar daun terminal, dan kecerahan helai daun. Ciri utama gerombol I yaitu memiliki kecerahan helai daun sedang, daun terminal panjang dan lebar. Ciri utama gerombol II yaitu memiliki intensitas pewarnaan antosianin ujung batang kuat, panjang daun terminal sedang, dan 
Tabel 5. Karakter ukuran daun 13 aksesi pohpohan

\begin{tabular}{|c|c|c|c|c|c|}
\hline \multirow[b]{2}{*}{ Aksesi } & \multicolumn{5}{|c|}{ Karakter } \\
\hline & $\begin{array}{c}\text { Panjang helai } \\
\text { daun }^{\text {a }}\end{array}$ & $\begin{array}{c}\text { Lebar helai } \\
\text { daun }^{\text {b }}\end{array}$ & $\begin{array}{c}\text { Panjang daun } \\
\text { terminal }^{\mathrm{c}}\end{array}$ & $\begin{array}{c}\text { Lebar daun } \\
\text { terminal }^{\mathrm{d}}\end{array}$ & $\begin{array}{c}\text { Panjang tangkai } \\
\text { daun }^{\mathrm{e}}\end{array}$ \\
\hline Warung Loa & Panjang & Lebar & Panjang & Lebar & Sedang \\
\hline Bobojong & Sedang & Sedang & Pendek & Sedang & Sedang \\
\hline Tugu Selatan & Panjang & Lebar & Panjang & Lebar & Sedang \\
\hline Palasari & Panjang & Lebar & Panjang & Lebar & Sedang \\
\hline Curug Rendeng & Panjang & Lebar & Sedang & Sedang & Sedang \\
\hline Langensari & Panjang & Lebar & Panjang & Lebar & Sedang \\
\hline kayu Ambon & Panjang & Lebar & Panjang & Lebar & Sedang \\
\hline Lebak Muncang & Panjang & Lebar & Panjang & Lebar & Sedang \\
\hline Argalingga & Panjang & Lebar & Panjang & Lebar & Sedang \\
\hline Linggarjati & Panjang & Lebar & Sedang & Sedang & Sedang \\
\hline Situsari & Panjang & Lebar & Sedang & Sedang & Sedang \\
\hline Sukalilah & Panjang & Lebar & Panjang & Lebar & Sedang \\
\hline Lebaksiuh & Panjang & Lebar & Panjang & Lebar & Sedang \\
\hline
\end{tabular}

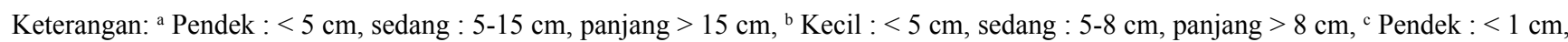
sedang : $1-2 \mathrm{~cm}$, panjang $>2 \mathrm{~cm},{ }^{\mathrm{d}}$ Kecil $:<0.3 \mathrm{~cm}$, sedang : $0.3-0.5 \mathrm{~cm}$, lebar $>0.5 \mathrm{~cm},{ }^{\mathrm{e}}$ Pendek $:<3 \mathrm{~cm}$, sedang : $3-5 \mathrm{~cm}$, panjang: $>5 \mathrm{~cm}$

Tabel 6. Karakter bunga 13 aksesi pohpohan

\begin{tabular}{|c|c|c|c|c|}
\hline \multirow[b]{2}{*}{ Aksesi } & \multicolumn{4}{|c|}{ Karakter } \\
\hline & $\begin{array}{c}\text { Panjang ruas } \\
\text { rata-rata batang } \\
\text { berbunga }^{\mathrm{a}}\end{array}$ & Bentuk bunga & $\begin{array}{c}\text { Warna daun mahkota } \\
\text { pada bunga }\end{array}$ & Waktu berbunga ${ }^{\mathrm{b}}$ \\
\hline Warung Loa & Sedang & Majemuk tak berbatas & Putih & Genjah \\
\hline Bobojong & Sedang & Majemuk tak berbatas & Putih & Genjah \\
\hline Tugu Selatan & Sedang & Majemuk tak berbatas & Putih & Genjah \\
\hline Palasari & Sedang & Majemuk tak berbatas & Putih & Genjah \\
\hline Curug Rendeng & Sedang & Majemuk tak berbatas & Putih & Genjah \\
\hline Langensari & Sedang & Majemuk tak berbatas & Putih & Genjah \\
\hline kayu Ambon & Sedang & Majemuk tak berbatas & Putih & Genjah \\
\hline Lebak Muncang & Sedang & Majemuk tak berbatas & Putih & Genjah \\
\hline Argalingga & Sedang & Majemuk tak berbatas & Putih & Genjah \\
\hline Linggarjati & Sedang & Majemuk tak berbatas & Putih & Genjah \\
\hline Situsari & Sedang & Majemuk tak berbatas & Putih & Genjah \\
\hline Sukalilah & Sedang & Majemuk tak berbatas & Putih & Genjah \\
\hline Lebaksiuh & Sedang & Majemuk tak berbatas & Putih & Genjah \\
\hline
\end{tabular}

Keterangan: ${ }^{a}$ Pendek $:<5 \mathrm{~cm}$, sedang : 5-10 cm, panjang : $>10 \mathrm{~cm},{ }^{\mathrm{b}}$ Sangat genjah $:<30$ hst, genjah : 30-60 hst, sedang : 61-90 hst, dalam : 91-120 hst, sangat dalam : $>120$ hst

kecerahan helai daun kuat. Ciri utama gerombol III yaitu memiliki panjang dan lebar daun sedang, daun terminal pendek, dan kecerahan helai daun lemah.

Berdasarkan hasil analisis gerombol maka dipilih masing-masing 1 aksesi untuk ditanam pada percobaan 2 antara lain Warung Loa (gerombol 1), Linggarjati (gerombol 2), dan Bobojong (gerombol 3). Aksesi Warung Loa dipilih karena merupakan aksesi komersial yang banyak dijual baik dipasar tradisional maupun swalayan, sedangkan aksesi Linggarjati dipilih karena merupakan aksesi dengan 


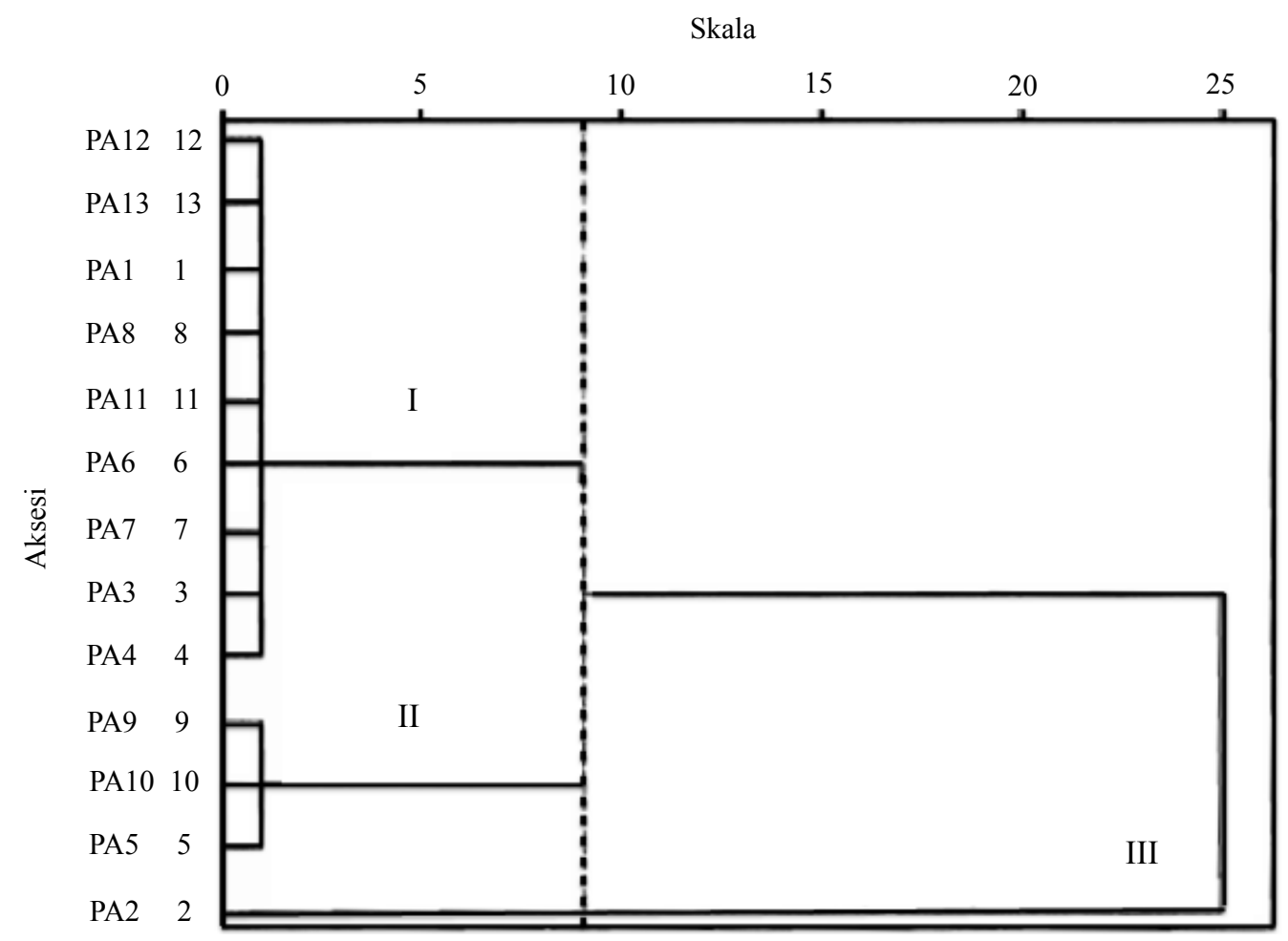

Gambar 1. Dendogram hasil analisis 13 aksesi pohpohan. PA1 = Warung Loa, PA2 = Bobojong, PA3 $=$ Tugu Selatan, PA4 = Palasari, PA5 $=$ Curug Rendeng, PA6 = Langensari, PA7 = Kayu Ambon, PA8 = Lebak Muncang, PA9 = Argalingga, PA10 = Linggarjati, PA11 $=$ Situsari, PA12 $=$ Sukalilah PA13 $=$ Lebaksiuh

persentase pertumbuhan yang paling tinggi dibanding aksesi Curug Rendeng dan Majalengka. Aksesi Bobojong dipilih karena pada gerombol I hanya ada 1 aksesi saja dan tidak ada pembandingnya.

\section{Evaluasi Potensi Produksi antar Aksesi Pohpohan Tinggi Tanaman, Diameter Batang, Jumlah Cabang Primer}

Berdasarkan hasil analisis ragam menunjukkan bahwa aksesi berpengaruh sangat nyata terhadap tinggi tanaman (Tabel 7). Aksesi Warung Loa merupakan aksesi paling tinggi $(37.27 \mathrm{~cm})$ sedangkan aksesi Bobojong merupakan aksesi paling pendek $(27.78 \mathrm{~cm})$. Tinggi tanaman diukur mulai dari permukaan tanah sampai titik tumbuh tertinggi pada umur 6 MST. Menurut Ogbomo dan Ajayi (2009) tinggi tanaman merupakan karakter pertumbuhan terpenting yang berhubungan langsung dengan produksi tanaman.

Aksesi berpengaruh nyata terhadap diameter batang dan jumlah cabang primer (Tabel 7). Aksesi Linggarjati merupakan aksesi dengan diameter batang terbesar $(0.29$ $\mathrm{cm})$ sedangkan diameter batang terkecil yaitu aksesi Bobojong $(0.20 \mathrm{~cm})$. Aksesi Warung Loa merupakan aksesi dengan jumlah cabang primer terbanyak yaitu 6 cabang sedangkan yang sedikit yaitu aksesi Bobojong 4 cabang. Banyaknya jumlah cabang diikuti dengan banyaknya pucuk yang bisa dipanen sehingga dapat meningkatkan produktivitas tanaman pohpohan. Menurut Islam etal. (2011) peningkatan produktivitas tanaman dapat di lakukan dengan memilih genotipe yang memiliki karakter percabangan yang banyak.
Panjang Daun, Lebar Daun, dan Umur Mulai Berbunga

Berdasarkan hasil analisis ragam menunjukkan bahwa aksesi berpengaruh sangat nyata terhadap panjang daun, lebar daun, dan umur mulai berbunga (Tabel 7). Panjang dan lebar daun pohpohan diamati pada daun yang telah membuka sempurna yaitu pada posisi daun keempat pada umur 6 MST. Masing-masing aksesi menunjukkan keragaan fisik daun yang baik. Menurut Joseph dan George (2011) keragaan fisik daun yang baik mengindikasikan pertumbuhan tanaman tersebut tumbuh dengan baik.

Aksesi Linggarjati merupakan aksesi dengan daun terpanjang $(14.72 \mathrm{~cm})$ dan aksesi Bobojong merupakan aksesi dengan daun terpendek $(8.63 \mathrm{~cm})$. Daun terlebar yaitu aksesi Warung Loa $(8.54 \mathrm{~cm})$ sedangkan daun terkecil yaitu aksesi Bobojong $(5.43 \mathrm{~cm})$. Panjang dan lebar daun dapat meningkatkan total boimassa tanaman. Hal ini sejalan dengan pendapat Adeoti et al. (2012) yang mengatakan bahwa panjang dan lebar daun berkolerasi positif terhadap total biomassa tanaman.

Umur mulai berbunga 3 aksesi pohpohan yang ditanam berkisar antara 41-52 hari setelah tanam (HST) (Tabel 7). Umur berbunga mulai dihitung ketika 50\% tanaman telah berbunga. Aksesi Warung Loa dan Linggarjati merupakan aksesi berbunga paling cepat yaitu 41 HST, sedangkan aksesi Bobojong merupakan aksesi berbunga paling lama yaitu 52 HST. Bunga dari masing-masing aksesi tidak satu pun membentuk buah sehingga tidak menghasilkan biji. 
Tabel 7. Tinggi tanaman, diameter batang, jumlah cabang primer panjang daun, lebar daun, dan umur berbunga 3 aksesi pohpohan

\begin{tabular}{lcccccc}
\hline & \multicolumn{1}{c}{ Peubah } \\
\cline { 2 - 8 } Aksesi & $\begin{array}{c}\text { Tinggi tanaman } \\
(\mathrm{cm})\end{array}$ & $\begin{array}{c}\text { Diameter } \\
\text { batang }(\mathrm{cm})\end{array}$ & $\begin{array}{c}\text { Jumlah cabang } \\
\text { primer }\end{array}$ & $\begin{array}{c}\text { Panjang daun } \\
(\mathrm{cm})\end{array}$ & $\begin{array}{c}\text { Lebar daun } \\
(\mathrm{cm})\end{array}$ & $\begin{array}{c}\text { Umur berbunga } \\
(\mathrm{HST})\end{array}$ \\
\hline Warung Loa & $37.27 \mathrm{a}$ & $0.27 \mathrm{a}$ & $6 \mathrm{a}$ & $13.62 \mathrm{a}$ & $8.54 \mathrm{a}$ & $41 \mathrm{~b}$ \\
Linggarjati & $35.65 \mathrm{a}$ & $0.29 \mathrm{a}$ & $4 \mathrm{~b}$ & $14.72 \mathrm{a}$ & $8.39 \mathrm{a}$ & $41 \mathrm{~b}$ \\
Bobojong & $27.78 \mathrm{~b}$ & $0.20 \mathrm{~b}$ & $4 \mathrm{~b}$ & $8.63 \mathrm{~b}$ & $5.43 \mathrm{~b}$ & $52 \mathrm{a}$ \\
\hline Uji F & $* *$ & $*$ & $*$ & $* *$ & $* *$ & $* *$ \\
\hline
\end{tabular}

Keterangan: Angka-angka yang diikuti dengan huruf yang sama pada kolom yang sama menunjukkan hasil yang tidak berbeda nyata berdasarkan DMRT pada $\alpha 5 \%$. * = berpengaruh nyata pada $\alpha 5 \%, * *=$ berpengaruh sangat nyata pada $\alpha 5 \%$

Hasil Panen per Petak dan Produktivitas Tanaman 3 Aksesi Pohpohan

Aksesi bepengaruh sangat nyata terhadap hasil panen per petak (Tabel 8). Total hasil panen terbanyak yaitu aksesi Warung Loa (1,486 g per petak) dan yang paling sedikit yaitu aksesi Bobojong (746.25 g per petak).

Panen dilakukan sebanyak 3 kali dengan intensitas panen 2 minggu sekali. Kriteria tanaman pohpohan siap dipanen yaitu panjang pucuk $15 \mathrm{~cm}$, daun hijau segar, tidak menggulung dan tidak ada bercak daun, memiliki 6-10 helai daun, batang yang dipetik masih getas, mudah patah, dan tidak berkayu.

Panen pertama masing-masing aksesi cenderung lebih rendah dibandingkan panen kedua dan ketiga, karena panjang pucuk yang tidak memenuhi kriteria panen. Panen kedua dan ketiga masing-masing aksesi mengalami peningkatan. Hal ini disebabkan oleh pemotongan pucuk pada saat panen pertama sehingga dapat merangsang pertumbuhan tunas-tunas baru. Pemotongan pucuk memicu bekerjanya meristem ujung yang menghasilkan sel-sel baru pada batang tanaman. Banyaknya pertumbuhan tunas meningkatkan hasil panen per petak.
Aksesi berpengaruh sangat nyata terhadap produktivitas tanaman (Tabel 8). Total produktivitas tanaman berkisar antara 1,475-2,889 $\mathrm{kg} \mathrm{ha}^{-1}$ (Tabel 8). Hasil ini lebih tinggi dibandingkan hasil penelitian Ekawati et al. (2010) mencapai produktivitas $360.50 \mathrm{~kg} \mathrm{ha}^{-1}$. Hal ini menunjukkan bahwa ketiga aksesi yang ditanam potensial dikembangkan dalam upaya peningkatan produktivitas tanaman pohpohan. Peningkatan produksi dapat dilakukan dengan pemilihan aksesi yang tepat dan unggul. Menurut Budi (2007) dan Adiyoga (2009) peningkatan produksi juga dapat dilakukan dengan mengoptimalkan populasi tanaman per satuan luas.

Masing-masing aksesi pohpohan memiliki keunggulan. Aksesi Warung Loa memiliki 5 keunggulan dari 8 peubah yang diamati yaitu tanaman tinggi, jumlah cabang primer banyak, daun lebar, hasil panen per petak tinggi, dan produktivitas tanaman tinggi. Aksesi Linggarjati memiliki 2 keunggulan dari 8 karakter yang diamati yaitu diameter batang besar dan berdaun panjang. Aksesi Bobojong memiliki 1 keunggulan dari 8 karakter yang diamati yaitu berbunga lama.

Tabel 8. Hasil panen per petak dan produktivitas tanaman 3 aksesi pohpohan

\begin{tabular}{|c|c|c|c|c|c|}
\hline \multirow[b]{2}{*}{ Aksesi } & \multicolumn{5}{|c|}{ Peubah pengamatan hasil panen per petak $(\mathrm{g})$ dan produktivitas tanaman $\left(\mathrm{kg} \mathrm{ha}^{-1}\right)$} \\
\hline & Panen I (g) & Panen II (g) & Panen III (g) & $\begin{array}{l}\text { Total panen per } \\
\text { petak }(\mathrm{g})\end{array}$ & $\begin{array}{c}\text { Total } \\
\text { produktivitas } \\
\text { tanaman }\left(\mathrm{kg} \mathrm{ha}^{-1}\right)\end{array}$ \\
\hline Warung Loa & $438.25 \mathrm{a}$ & $459.75 a$ & $546.75 \mathrm{a}$ & $1,486.00 \mathrm{a}$ & $2,889.00 \mathrm{a}$ \\
\hline Linggarjati & $431.25 b$ & $448.25 b$ & $508.75 b$ & $1,431.00 \mathrm{~b}$ & $2,776.00 \mathrm{~b}$ \\
\hline Bobojong & $228.25 \mathrm{c}$ & $249.75 c$ & $259.75 \mathrm{c}$ & $746.25 \mathrm{c}$ & $1,475.00 \mathrm{c}$ \\
\hline $\mathrm{Uji} F$ & $* *$ & $* *$ & ** & $* *$ & $* *$ \\
\hline
\end{tabular}

Keterangan: Angka-angka yang diikuti dengan huruf yang sama pada kolom yang sama menunjukkan hasil yang tidak berbeda nyata berdasarkan DMRT pada $\alpha 5 \%$.* = berpengaruh sangat nyata pada $\alpha 1 \%$, Panen I : 6 mst, Panen II : 8 mst, Panen III : $10 \mathrm{mst}$

\section{KESIMPULAN}

Berdasarkan analisis gerombol pada skala kemiripan sembilan, 13 aksesi pohpohan hasil eksplorasi dikelompokkan menjadi tiga gerombol. Gerombol I terdiri atas Warung Loa, Tugu Selatan, Palasari, Langensari, Kayu Ambon, Lebak Muncang, Situsari, Sukalilah dan Lebaksiuh. Gerombol II terdiri atas Curug Rendeng, Argalingga, dan 
Linggarjati. Gerombol III adalah Bobojong. Berdasarkan uji lanjut Duncan Multiple Range Test (DMRT), aksesi Warung Loa merupakan aksesi yang paling unggul karena menunjukkan hasil yang terbaik pada tinggi tanaman, jumlah cabang primer, lebar daun, hasil panen per petak, dan produktivitas tanaman.

\section{UCAPAN TERIMA KASIH}

Terima kasih disampaikan kepada Kemenristek yang telah mendanai penelitian ini melalui Hibah Insentif Riset SINas Tahun 2014 an. Pusat Kajian Hortikultura Tropika (PKHT). Nomor 25/SEK/INSINAS/PPK/I/2014.

\section{DAFTAR PUSTAKA}

Adeoti,K.,A.Dansi,L.Ahoton, R. Vodouhe, B.C.Ahohuendo, A. Rival, A. Sanni. 2012. Agromorphological characterization of Sesamum radiatum neglected and underutilized species of traditional leafy vegetable of great importance in Benin. Afr. J. Agric. Res. 7:35693578 .

Andarwulan, N., R. Batari, D.A. Sandrasari, B. Bolling, H. Wijaya. 2010. Flavonoid content and antioxidant activity of vegetables from Indonesia. Food Chem. 121:1231-1235.

Adiyoga, W. 2009. Analisis trend hasil per satuan luas tanaman sayuran Tahun 1969-2006 di Indonesia. J. Hort. Indonesia 19:484-499.

Ariawan, I.A., I.E.N. Kencana, N.P. Sucipta. 2013. Komparasi analisis gerombol (cluster) dan biplot dalam pengelompokan. J. Matematika 2:17-22.

Basha, S.D., M. Sujatha. 2007. Inter and intra-population variability of Jatropha curcas (L.) characterized by RAPD and ISSR markers and development of population specific SCAR markers. Euphytica 156:375-386.

Budi, L.S. 2007. Pengaruh cara tanam dan penggunaan varietas terhadap produktivitas wijen (Sesamum indicum L.). Bul. Agron. 35:135-141.

Ekawati, R., A.D. Susila, J.G. Kartika. 2010. Pengaruh naungan tegakan pohon terhadap pertumbuhan dan produktivitas beberapa tanaman sayuran indigenous. J. Hort. Indonesia 1:46-52.

Endrini, S. 2011. Antioxidant activity and anticarcinogenic properties of rumput mutiara (Hedyotis corymbosa (L.) Lam.) and pohpohan (Pilea tinervia (Roxb.) Wight.). J. Med. Plant Res. 5:3715-3718.

Indriani, F.C., A.N. Sudjindro, Sugihanto, L. Soetopo. 2008. Keragaman genetik plasma nutfah kenaf (Hibiscus cannabinus L.) dan beberapa spesies yang sekerabat berdasarkan analisis isozim. Agritek. 6:1793-1802.

Islam, A.K., M.N. Anuar, Z. Yaakob, M. Osman. 2011. Heterosis for seed yield and its components in Jatropha (Jatropha curcas L.). Int. J. Plant. Breed. 5:74-79.

Joseph, L., M. George. 2011. Pharmacognostical profiling of Geranum ocellatum leaves. Int. J. Med. Arom. Plants 1:351-354.

Monro, A.K. 2004. Three new species and three new name in Pilea (Urticaceae) from New Guinea. Kew Bull. 59:573-579.

Monro, A.K., Y.G. Wei, C.J. Chen. 2012. Three new species of Pilea (Urticaceae) from limestone karst in China. Phytokeys 19:51-66.

Ogbomo, K.E.L., S.O. Ajayi. 2009. Growth and yield performance of Amaranthus cruentus influenced by planting density and poultry manure application. Not. Bot. Hort. Agrobot. Cluj 37:195-199.

Opabode, J.T., O.C. Adebooye. 2005. Aplication of biotechnology for the improvement of Nigerian indigenous leaf vegetables. Afr. J. Biotechnol. 4:138142.

Putrasamedja, S. 2005. Eksplorasi dan koleksi sayuran indigenous di Kabupaten Karawang, Purwakarta, dan Subang. Bul. Plasma Nutfah 11:16-20.

Ram, S.G., K.T. Parthiban, R.S. Khumar, V. Thiruvengadam, M. Paramathma. 2008. Genetic diversity among jatropha species as revealed by RAPD markers. Genet Resour. Crop. Evol. 55:803-809.

Santosa, E., V. Prawati, Sobir, Y. Mine, N. Sugiyana. 2015. Agronomy, utilization and economics of indigenous vegetable in West Java, Indonesia. J. Hort. 6:125134.

Susantidiana, A. Wijaya, B. Lakitan, M. Surahman. 2009. Identifikasi beberapa aksesi jarak pagar (Jatropha curcas L.) melalui analisis RAPD dan morfologi. J. Agron. Indonesia 37:167-173.

Tjitrosoepomo, G. 1987. Morfologi Tumbuhan. UGM, Yogyakarta.

Yunianti, R., S. Sastrosumarjo, S. Sujiprihati, M. Surahman, S.H. Hidayat. 2007. Ketahanan 22 genotipe cabai (Capsicum spp.) terhadap Phytophthora capsici Leonian dan keragaman genetiknya. Bul. Agron. 35:103-111. 